\title{
Transvitreal fine needle aspiration biopsy: the influence of intraocular lesion size on diagnostic biopsy result
}

\begin{abstract}
Purpose To determine the efficacy of transvitreal biopsy in the diagnosis of suspected intraocular malignancy and simulating conditions.

Methods We performed a retrospective study of the case notes from patients who underwent pars plana transvitreal biopsy from July 1986 to October 1999. We studied the relationship between lesion thickness as measured by Ascan ocular ultrasound and the incidence of a successful diagnostic biopsy. We assessed the diagnostic accuracy by comparing the biopsy result with the histological examination of any subsequently enucleation specimens and noted the incidence and severity of complications attributable to the biopsy. Results A total of 83 biopsies were performed for choroidal masses. There was insufficient material for cytological examination in $\mathbf{1 0}$ cases, and sufficient material in $\mathbf{7 3}$ cases (an overall diagnostic report rate was $88 \%$ ). There was a strong correlation ( $p=\mathbf{0 . 0 0 0 4}$,

Mann-Whitney $U$-test) between a diagnostic biopsy result and the thickness of the lesion on A-scan ultrasound: a biopsy was diagnostic in only $40 \%$ (4 of 10 ) of choroidal lesions less than $1.99 \mathrm{~mm}$ thick, whereas biopsies taken from lesions between 2.00 and $4.00 \mathrm{~mm}$ thick were diagnostic in $90 \%$ of cases (27 of 30 ). In thicker lesions of $4 \mathrm{~mm}$ or more the cell aspirate was sufficient to make a diagnosis in $98 \%$ (42 of 43). Following diagnostic biopsy 27 patients had their tumours resected, and the histology results following enucleation confirmed the cytological diagnosis of malignancy in $96 \%$ of these cases (26 of 27 ). Conclusion Transvitreal biopsy is a highly accurate diagnostic procedure with a low complication rate. It is a reliable diagnostic tool in suspicious choroidal lesions greater than $\mathbf{2} \mathbf{~ m m}$ thick.
\end{abstract}

Key words A-scan ultrasound, Cytology, Fine needle aspiration biopsy (FNAB), Histology, Malignant melanoma (MM), Ocular oncology
V.M.L. COHEN, S. DINAKARAN, M.A. PARSONS, I.G. RENNIE
Fine needle aspiration biopsy (FNAB) is a diagnosic tool used to distinguish between suspected intraocular malignancy and simulating conditions. It is an invasive technique, and its use should therefore be limited to lesions where the diagnosis can not be made on the basis of fundoscopy, ultrasound and fluorescein or indocyanine green angiography. Transvitreal biopsy is only performed on a small minority of patients with a suspected intraocular malignancy because experienced ocular oncologists have a high level of diagnostic accuracy using non-invasive techniques. ${ }^{1}$ However, some metastastic tumours have an atypical presentation, ${ }^{2,3}$ and amelanotic melanomas, benign and

inflammatory lesions may simulate metastases in the choroid.

In our department the following indications are used to select patients for posterior segment transvitreal biopsy:

- major diagnostic uncertainty,

- amelanotic mass detected with a history of previous non-ocular malignancy,

- patient refusing definitive treatment until malignancy is confirmed,

- suspected re-growth following treatment of ocular melanoma.

Sampling and interpretation errors can occur; therefore, the results following FNAB must be interpreted with caution and in the clinical context of the lesion. FNAB does not yield the same prognostic information as an enucleation specimen. ${ }^{4}$

The major limitation of transvitreal biopsy is the difficulty in obtaining a large enough specimen for cytological analysis. ${ }^{5,6}$ Examination of only a few aspirated cells may be diagnostic in the hands of an experienced ophthalmic pathologist, but a larger specimen will improve the chances of a diagnostic biopsy. ${ }^{7}$ The aim of this study was to investigate the relationship between the incidence of a diagnostic biopsy and tumour thickness.

\author{
V.M.L. Cohen \\ S. Dinakaran \\ I.G. Rennie \\ Department of \\ Ophthalmology \\ Royal Hallamshire Hospital \\ Sheffield, UK
}

M.A. Parsons

Ophthalmic Sciences Unit University of Sheffield Sheffield, UK

Miss Victoria Cohen

40 Farley Road Derby DE23 6BW, UK

Tel: +44 (0)1332 340703 e-mail:

victoria-cohen@supanet.com

Received: 14 September 2000

Accepted in revised form:

20 November 2000 
Table 1. Appearance and differential diagnosis of choroidal lesions for fine needle aspiration biopsy

\begin{tabular}{|c|c|c|c|}
\hline No. & Appearance & Differential diàgnosis & Indication \\
\hline 34 & Pigmented mass & $\begin{array}{l}\text { Naevus } \\
\text { Suspicious naevus } \\
\text { Melanocytoma } \\
\text { Disciform maculopathy } \\
\text { Choroidals } \\
\text { Melanoma }\end{array}$ & $\begin{array}{l}\text { Diagnostic uncertainty } \\
\text { Patient request for tissue diagnosis } \\
\text { Re-growth following radiotherapy in } 4 \text { cases }\end{array}$ \\
\hline 34 & Amelanotic mass & $\begin{array}{l}\text { Haemangioma } \\
\text { Amelanotic melanoma } \\
\text { Metastases } \\
\text { Osteoma } \\
\text { Granuloma }\end{array}$ & $\begin{array}{l}\text { Diagnostic uncertainty } \\
\text { Patient request for tissue diagnosis } \\
\text { History of non-ocular malignancy in } 10 \text { cases }\end{array}$ \\
\hline 9 & $\begin{array}{l}\text { Vitreous haemorrhage } \\
\text { choroidal mass on ultrasound }\end{array}$ & $\begin{array}{l}\text { Haemorrhage in disciform maculopathy } \\
\text { Melanoma } \\
\text { Metastasis }\end{array}$ & Diagnostic uncertainty \\
\hline 6 & Vitritis and subretinal plaques & $\begin{array}{l}\text { Posterior uveitis } \\
\text { Posterior scleritis } \\
\text { Benign reactive lymphoid hyperplasia } \\
\text { Lymphoma }\end{array}$ & Diagnostic uncertainty \\
\hline
\end{tabular}

\section{Technique and instrumentation}

Transvitreal FNAB may be performed by a number of different techniques. In our department the procedure is performed under retrobulbar anaesthesia using the operating microscope and an irrigating contact lens. No fibre optic light source is required. The conjunctiva is recessed to expose the sclerotomy site. The sclera is cauterised and a pars planar stab incision made through full-thickness sclera at $3.5 \mathrm{~mm}$ from the limbus.

A 25 gauge long needle is connected to a $50 \mathrm{~cm}$ manometer tubing with a $5 \mathrm{ml}$ or $10 \mathrm{ml}$ syringe on the end to generate the vacuum. The suspected tumour is approached via an indirect route from the opposite quadrant. The needle is passed into the lesion and then slowly advanced whilst the plunger of the syringe is withdrawn by the assistant. The suction is then released and the needle removed. Some cytology transport fluid (Shandon, UK) is aspirated into the hub of the needle before injection directly into the cytology container. This may be repeated up to three times to ensure an adequate specimen. The scleral port and conjunctiva are sutured and an injection of subconjunctival cefuroxime is given at the end of the procedure.

\section{Methods}

Fine needle aspiration biopsies of posterior segment lesions were studied from July 1986 to October 1999. All the biopsies were performed by the same surgeon (I.G.R.), and cytological analysis by a single ophthalmic pathologist (M.A.P.). A retrospective analysis of the case

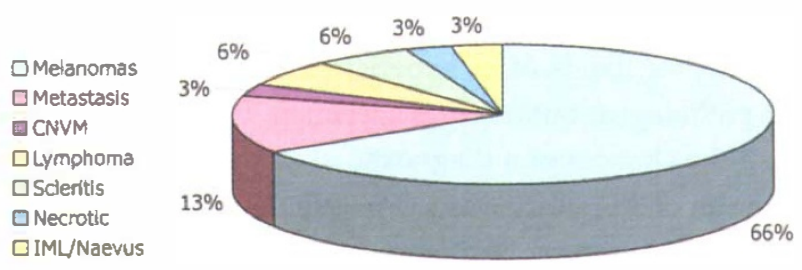

Fig. 1. Range of diagnoses at biopsy. notes was performed, recording the description of a suspected intraocular tumour, A- and B-scan ultrasound measurements and differential diagnosis at presentation. The original indication for biopsy was also obtained from the case notes. Any complications following transvitreal fine needle aspiration biopsy were noted. The results of the transvitreal biopsy and any subsequent histological results were recorded.

Cytology results were compared with the histological diagnosis. The incidence of a diagnostic biopsy was correlated with tumour thickness on A-scan measurements. The data were statistically analysed using the non-parametric Mann-Whitney $U$-test.

\section{Results}

A total of 83 biopsies were performed: 42 on left eyes and 41 right eyes. The fundus appearance and differential diagnosis are shown in Table 1. An equal number of biopsies were performed for pigmented and nonpigmented choroidal lesions. Nine patients presented with a vitreous haemorrhage and a choroidal mass on the ultrasound scan. These patients underwent a three-port pars planar core vitrectomy; the biopsy was then completed using the same technique as in all other patients. Fig. 1 shows the range of diagnoses at biopsy. The biopsy result confirmed the primary differential diagnosis at presentation in $84 \%$ of cases (61 of 73).

Histological data were available on 27 eyes which underwent enucleation or exenteration. Cytology confirmed the histology result in 96\% (26 of 27 ) (Table 2). The one exception was a diagnostic error, where the biopsy was reported as an amelanotic, spindle B cell, malignant melanoma, but the enucleated specimen revealed prostatic adenocarcinoma. This discrepancy arose because of the biopsy yielded a very small number of cells, and consequently there was insufficient material for immunohistochemistry to distinguish between epithelial cells and melanocytes. 


\begin{tabular}{lll}
\hline Case & Cytology report & Histology result \\
\hline 1 & Epithelioid cell MM $\mathrm{MM}^{a}$ & MM confirmed, epithelioid/mixed \\
2 & Spindle A and B cell MM & MM confirmed, spindle B \\
3 & Spindle B cell MM & Prostatic adenocarcinoma \\
4 & Spindle B cell MM & MM confirmed, spindle B \\
5 & Spindle B cell MM & MM confirmed, spindle B \\
6 & Epithelioid cell MM & MM confirmed, epithelioid/mixed \\
7 & Spindle cell MM & MM confirmed \\
8 & Spindle cell MM & MM confirmed \\
9 & Spindle cell MM & MM confirmed, spindle B \\
10 & Epithelioid cell MM & MM confirmed, epithelioid \\
11 & Spindle cell MM & MM confirmed, epithelioid \\
12 & Mixed cell MM & MM confirmed, mixed \\
13 & Spindle cell MM & MM confirmed \\
14 & Spindle B cell MM & MM confirmed, spindle A/B \\
15 & Spindle B cell MM & MM confirmed, spindle B \\
16 & Mixed cell MM & MM confirmed \\
17 & Adenocarcinoma & Prostatic adenocarcinoma confirmed; perforated globe, necrotising scleritis, \\
& & Staphylococcus aureus \\
18 & Mixed cell MM & MM confirmed, mixed \\
19 & Spindle B cell MM & MM confirmed, spindle B \\
20 & Epithelioid cell MM & MM confirmed, mixed \\
21 & Mixed cell MM & MM confirmed, mixed \\
22 & Mixed cell MM & MM confirmed, mixed \\
23 & Mixed cell MM & MM confirmed, mixed \\
24 & Epithelioid cell MM & MM confirmed, epithelioid \\
25 & Mixed cell MM & MM confirmed, mixed \\
26 & Spindle B cell MM & MM confirmed, spindle B \\
27 & Spindle B cell MM & MM confirmed, spindle B \\
\hline
\end{tabular}

MM, malignant melanoma.

${ }^{a}$ Cases where immunohistochemistry was performed.

Sufficient cells were obtained to make a diagnosis in 73 of 83 biopsies, giving an overall diagnostic report rate of $88 \%$. There were insufficient cells for diagnosis in only 10 biopsies; 6 lesions in this group were described clinically as small suspicious naevi or indeterminate melanocytic lesions; 3 lesions were amelanotic (1 patient had been treated for breast carcinoma, another for bladder carcinoma); 1 patient underwent biopsy for suspected recurrence of a choroidal melanoma following stereotactic radiosurgery. Of these 10 patients, one had a repeat FNAB which was diagnostic, 4 were treated as having malignant melanomas with argon laser, ruthenium plaque or proton beam radiotherapy and 5 were observed closely in clinic. One pigmented mass under close observation was found to grow through the biopsy site several months after the biopsy; a small choroidal malignant melanoma was diagnosed and treated with argon laser.

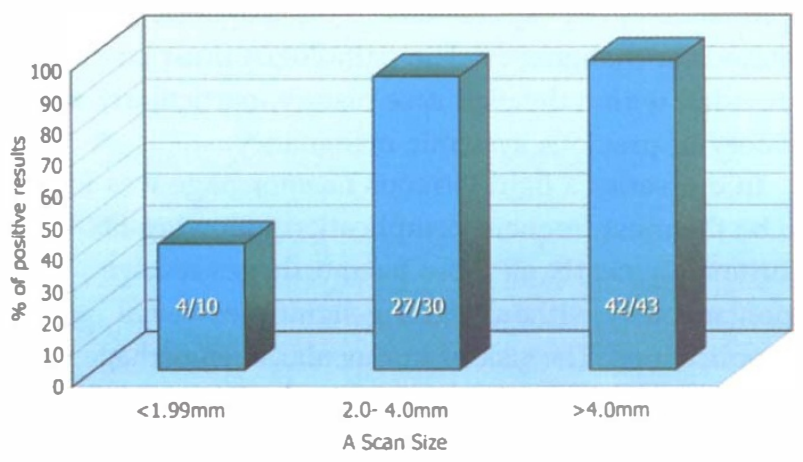

Fig. 2. Diagnostic biopsy correlated with the A-scan measurement.
The lesions that underwent biopsy ranged from $1 \mathrm{~mm}$ to $15.8 \mathrm{~mm}$ thick on A-scan ultrasound (mean $5.3 \mathrm{~mm}$, mode $4.0 \mathrm{~mm}$ ). The minimum resolution of the A-scan ultrasound was $0.01 \mathrm{~mm}$. There was a very strong relationship between increasing lesion thickness and the incidence of a diagnostic biopsy result (Mann-Whitney $U$-test, $p=0.0004$ ).

The cell aspirate was sufficient for diagnosis in $40 \%$ (4 of 10) of lesions less than $2 \mathrm{~mm}$ thick, in $90 \%$ (27 of 30 ) of lesions between 2 and $4 \mathrm{~mm}$ thick, and $98 \%$ (42 of 43) in more than $4 \mathrm{~mm}$ thick (Fig. 2).

Every biopsy resulted in a small haemorrhage at the biopsy site, which was controlled by digital pressure on the eye. The complications seen following FNAB are illustrated in Fig. 3. Vitreous haemorrhage occurred in $24 \%$, but all resolved spontaneously within 3 weeks, except in one case of persistent vitreous haemorrhage which required vitrectomy. The first FNAB performed in the Ocular Oncology Unit was complicated by endophthalmitis. This was was performed by indirect ophhalmoscopy, the conjunctiva was not recessed and no subconjunctival antibiotic was given. Following this

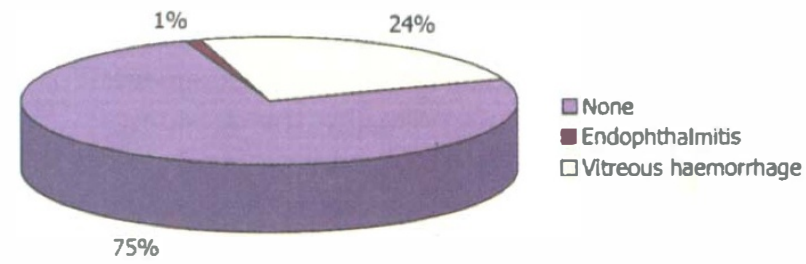

Fig. 3. Complication rate. 
complication the surgical technique was modified, and all subsequent biopsies were performed as described under Techniques and Instrumentation.

Retinal detachment was not seen following transvitreal FNAB in this series. The seeding of discrete tumour cells along the biopsy tract and local extraocular seeding is a theoretical risk following FNAB. However, no clinical evidence of new tumour growth within the scleral needle tracts or in the subconjunctival space was found in our series.

\section{Discussion}

We have demonstrated that the aspiration of sufficient cells for a diagnosis at FNAB is dependent on the thickness of the lesion. This is probably because the surgeon is able to advance the needle further into a relatively thick choroidal mass without fear of perforating the underlying sclera.

FNAB is most likely to provide a cytological diagnosis when lesions are greater than $2 \mathrm{~mm}$ thick. The results of this study are useful in the selection of patients for FNAB. One may argue that on clinical grounds choroidal naevi are rarely considered melanomas unless greater than $2 \mathrm{~mm}$ thick and that biopsy is not justified until they reach this size. However, some malignant melanomas are thin, atypical, diffusely spreading lesions. In addition FNAB is used in the diagnosis of a range of choroidal pathologies including inflammatory, infective benign and malignant conditions. Our '2-mm guideline' is particularly useful when advising patients who request tissue confirmation of malignancy before treatment.

Char et al. ${ }^{8}$ studied the number of cells obtained at FNAB, but they were unable to find any association with tumour diameter. Aggressive malignant melanomas are composed of less cohesive epithelioid cells, and therefore one might expect that suction during biopsy would produce larger cell aspirates in these cases. However, no association has been demonstrated between biopsy size and survival data, which might support this expectation. $^{9}$

We have shown that a diagnosis by FNAB could be achieved in 73 of 83 biopsies ( $88 \%$ ) overall, although the diagnosis rate rises to $94 \%$ if lesions more than $2 \mathrm{~mm}$ thick are selected. This high diagnostic biopsy rate is dependent on surgical technique. We believe there are several aspects to the technique that enable an adequate cell sample to be obtained. Firstly, when the surgeon is unable to see any material in the cytology transport fluid container several separate passes into the lesion should be made; up to three passes with the needle have been made to achieve an adequate specimen. Secondly, the suction generated by the syringe should be maintained whilst the needle is advanced by small incremental movements into the lesion. Thirdly, the operating microscope should be used to maintain good visualisation and the irrigating contact lens should be used to stabilise the eye and ensure good surgical control during the procedure.
Our overall diagnostic report rate of $88 \%$, and selective rate of $94 \%$ for lesions more than $2 \mathrm{~mm}$ in height, compares favourably with previous studies. Shields et al..$^{5}$ reported adequate material for diagnosis in $88 \%$ of patients, Augsburger achieved a diagnostic report rate of $68 \%$ for small choroidal lesions, ${ }^{6}$ and $89.5 \%$ in a series of 19 patients. ${ }^{10}$ In these studies the biopsies were performed using an indirect ophthalmoscope to visualise the fundus with the inherent difficulty of operating on a vertically and horizontally inverted retinal image. With this technique no contact lens is used, but the surgeon may use toothed forceps or traction sutures to stabilise the eye. ${ }^{10}$

Shields et al. ${ }^{5}$ improved their diagnostic report rate by using a larger 22 gauge needle. However, intraocular haemorrhage and tumour seeding are more common with larger-gauge needles. ${ }^{9,11}$ We believe a 25 gauge needle is large enough to obtain sufficient cells whilst being fine enough to cause minimal disturbance to the tissue. Augsburger ${ }^{10}$ suggested using a 10 or $20 \mathrm{ml}$ syringe for greater aspiration to obtain a larger biopsy specimen. However, we were able to achieve adequate aspirates with a $5 \mathrm{ml}$ syringe.

The transvitreal FNAB result confirmed the histological findings in all but one case and hence the diagnostic accuracy of FNAB was $96 \%$ (26 of 27). Previous authors ${ }^{5}$ have discussed the 'specificity' and 'sensitivity' of FNAB but the absolute calculation of these values depends crucially on having a confirmatory histological tissue diagnosis from enucleation specimens in all cases, regardless of whether the biopsy is benign or malignant.

There was only one case where the cytology results differed from the histology. This occurred because the cell aspirate was very small (the choroidal lesion was only $3 \mathrm{~mm}$ thick) and immunohistochemistry could not be performed on the amelanotic tumour. When the histopathological diagnosis became known the cytological specimen was re-evaluated and the cell aspirate was felt to be consistent with adenocarcinoma. Cytopathological diagnosis can be difficult and it is unlikely that errors of this type will ever be completely eliminated, ${ }^{12}$ especially if small numbers of cells are aspirated. To reduce the frequency of these errors FNAB of intraocular lesions should only be performed in departments with specialist ophthalmic pathologists and ophthalmologists experienced in the diagnosis of intraocular malignancy. The pathologist must be provided with a detailed case history, particularly any history of previous systemic malignancy.

In our series a light vitreous haemorrhage was found to be the most frequent complication following FNAB. Fortunately nearly all these haemorrhages resolve spontaneously without causing significant visual complications. The risk of intraocular haemorrhage can be reduced by avoiding manipulation of the globe during the procedure. This is achieved by using an irrigating contact lens to stabilise the eye, and the connector tubing 
to the syringe prevents the direct transmission of the force required to generate aspiration. Retinal vessels need to be avoided when selecting the biopsy site.

There were no cases of retinal detachment following FNAB, and others reporting this finding have suggested that a small local haemorrhage at the biopsy site plugs the hole in the retina preventing detachment. ${ }^{5}$ Some surgeons use a fibre optic light source when performing a transvitreal biopsy, ${ }^{13}$ but we achieved adequate illumination from the operating microscope. The technique reported in this paper involves minimal disturbance to the vitreous gel, which reduces the risk of a post-operative retinal detachment.

FNAB has a potential risk of seeding tumour cells along the biopsy tract or into the blood stream. However, few incidences of needle tract seeding in the biopsy of various other organs have ever been reported. ${ }^{14}$ Tumour cells seeding has been demonstrated within the scleral needle tracts, ${ }^{15}$ but the number of cells found is less than required for tumour growth in experimental animals. ${ }^{9}$ The risk of seeding is reduced by using a transocular indirect approach ${ }^{9}$ rather than the direct transscleral approach. The needle is inserted though the pars plana in a quadrant opposite the location of the tumour. The withdrawing sweeping action though the vitreous removes any loose cells adherent to the needle. We practise this technique and no cases of tumour seeding have been reported to date.

We have shown that FNAB is a useful diagnostic tool for atypical suspicious choroidal lesions in a highly selected group of patients. The procedure has a high diagnostic accuracy confirmed on histological examination of enucleation specimens. The results are highly dependent on the interpretation by an experienced specialist ocular cytopathologist. We therefore believe this procedure should be restricted to specialised ocular oncology centres with a specialist ophthalmic cytopathologist.

The main limitation of FNAB is the difficulty in obtaining a large enough specimen for cytological diagnosis. We have summarised the surgical technique used to obtain sufficient cells, and we have demonstrated that choroidal lesions which are more than $2 \mathrm{~mm}$ thick are more likely to yield a sufficient biopsy specimen for tissue diagnosis.

\section{References}

1. Shields JA. Diagnosis and management of intraocular tumors. St Louis: CV Mosby, 1983:18-39, 172, 278-321.

2. Stephens RF, Shields JA. Diagnosis and management of cancer metastatic to the uvea: a study of 70 cases: Ophthalmology 1976;86:1336-49.

3. Ferry AP, Font RL Carcinoma metastatic to the eye and orbit: a clinicopathologic study of 227 cases. Arch Ophthalmol 1974;92:276-86

4. Folberg R, Augsburger JJ, Gamel JW, Shields JA, Lang WR. Fine needle aspirates of uveal melanomas and prognosis. Am J Ophthalmol 1985;100:654-7.

5. Shields JA, Shields CL, Ehya H, Eagle RC, De Potter P. Fineneedle aspiration biopsy of suspected intraocular tumours. Ophthalmology 1993;11:1677-83.

6. Augsburger JJ, Schneider S, Ehya H. The role of transviteral fine-needle aspiration biopsy in small suspected choroidal melanomas. Invest Ophthalmol Vis Sci 1999;40:1287.

7. Johnson WW, Elson CE. Respiratory Tract. In: Bibbo M, editor. Comprehensive cytopathology. Philadelphia: WB Saunders, 1991:320-98.

8. Char DH, Kroll SM, Miller T, Vastro J, Quivey J. Irradiated uveal melanomas: cytopathologic correlation with prognosis Am J Ophthalmol 1996;122:509-13.

9. Glasgow BJ, Brown HH, Zargoza AM, Foos RY. Quantification of tumour seeding from fine needle aspiration of ocular melanomas. Am J Ophthalmol 1988;105:538-46.

10. Augsburger JJ. Fine needle aspiration biopsy of suspected metastatic cancers to the posterior uvea. Trans Am Ophthalmol Soc 1988;86:499-560.

11. Jakobeic FA, Coleman DJ, Chattock A, Smith M. Ultrasonically guided needle biopsy and cytologic diagnosis of solid intraocular tumours. Ophthalmology 1979;86:1662-73.

12. Hajdu SI, Malamed MR. Limitations of aspiration cytology in the diagnosis of primary neoplasms. Acta Cytol 1984;28:337-45

13. Augsburger JJ, Shields JA. Fine needle aspiration biopsy of solid intraocular tumors: indications, instrumentation and techniques. Ophthalmic Surg 1984;15:34-40.

14. Tao LC, Pearson FG, DeLarue NC, et al. Percutaneous fineneedle aspiration biopsy: its value to clinical practice. Cancer 1980;45:1480-5.

15. Karcioglu ZA, Gordon RA, Karcioglu GL. Tumour seeding in ocular fine needle aspiration biopsy. Ophthalmology 1985;92:1763-6. 